\title{
Can reactivity to stress and family environment explain memory and executive function performance in early and middle childhood?
}

\author{
Reatividade ao estresse e ambiente familiar podem explicar o desempenho em \\ memória e funções executivas na primeira infância e na idade escolar?
}

\author{
Luciane da Rosa Piccolo, ${ }^{1}$ Jerusa Fumagalli de Salles, ${ }^{1}$ Olga Garcia Falceto, ${ }^{2}$ Carmen Luiza Fernandes, ${ }^{3}$ \\ Rodrigo Grassi-Oliveira ${ }^{4}$
}

\begin{abstract}
Introduction: According to the literature, children's overall reactivity to stress is associated with their socioeconomic status and family environment. In turn, it has been shown that reactivity to stress is associated with cognitive performance. However, few studies have systematically tested these three constructs together.

Objective: To investigate the relationship between family environment, salivary cortisol measurements and children's memory and executive function performance.

Method: Salivary cortisol levels of 70 children aged 9 or 10 years were measured before and after performing tasks designed to assess memory and executive functions. Questionnaires on socioeconomic issues, family environment and maternal psychopathologies were administered to participants' families during the children's early childhood and again when they reached school age.

Results: Data were analyzed by calculating correlations between variables and conducting hierarchical regression. High cortisol levels were associated with poorer working memory and worse performance in tasks involving executive functions, and were also associated with high scores for maternal psychopathology (during early childhood and school age) and family dysfunction. Family environment variables and changes in cortisol levels explain around $20 \%$ of the variance in performance of cognitive tasks.

Conclusion: Family functioning and maternal psychopathology in early and middle childhood and children's stress levels were associated with children's working memory and executive functioning. Keywords: Socioeconomic status, family environment, maternal psychopathology, cortisol, stress, neuropsychological assessment.
\end{abstract}

\section{Resumo}

Introdução: De acordo com a literatura, o nível socioeconômico e o ambiente familiar estão associados à reatividade ao estresse na criança. Essa reatividade ao estresse, por sua vez, tem sido associada com desempenho cognitivo. No entanto, poucos estudos testaram sistematicamente esses três construtos ao mesmo tempo.

Objetivo: Investigar a relação entre ambiente familiar, medidas de cortisol salivar e desempenho em memória e funções executivas das crianças.

Método: Os níveis de cortisol salivar de 70 crianças com idade entre 9 e 10 anos foram medidos antes e depois de tarefas de memória e funções executivas. As famílias dos participantes completaram questionários sobre questões socioeconômicas, ambiente familiar e psicopatologia materna durante a primeira infância e a idade escolar da criança.

Resultados: Correlações e regressão hierárquica foram realizadas para análise de dados. Níveis de cortisol elevados, bem como alta psicopatologia materna (na primeira infância e em idade escolar) e disfunção familiar foram associados com baixo desempenho em tarefas de funções executivas e memória de trabalho. As variáveis ambiente familiar e alterações nos níveis de cortisol explicam cerca de $20 \%$ da variação no desempenho de tarefas cognitivas.

Conclusão: $O$ funcionamento familiar e a psicopatologia materna no início e meio da infância, bem como os níveis de estresse das crianças, foram associados com a memória de trabalho e o funcionamento executivo das crianças.

Descritores: Nível socioeconômico, ambiente familiar, psicopatologia materna, cortisol, estresse, avaliação neuropsicológica.

\footnotetext{
${ }^{1}$ Departamento de Psicologia, Universidade Federal do Rio Grande do Sul (UFRGS), Porto Alegre, RS, Brazil. 2 Departamento de Psiquiatria e Medicina Legal, UFRGS, Porto Alegre, RS, Brazil. ${ }^{3}$ Grupo Hospitalar Conceição (GHC), Porto Alegre, RS, Brazil. ${ }^{4}$ Departamento de Psicologia, Pontifícia Universidade Católica do Rio Grande do Sul (PUCRS), Porto Alegre, RS, Brazil. This paper is part of the first author's doctoral dissertation, entitled "Family environment, stress and neuropsychological performance of children," presented on March 14, 2014, at Universidade Federal do Rio Grande do Sul (UFRGS), Porto Alegre, RS, Brazil. Financial support: Coordenação de Aperfeiçoamento de Pessoal de Nível Superior (CAPES).

Submitted Dec 08 2015, accepted for publication Dec 18 2015. No conflicts of interest declared concerning the publication of this article.

Suggested citation: Piccolo LR, Salles JF, Falceto OG, Fernandes CL, Grassi-Oliveira R. Can reactivity to stress and family environment explain memory and executive function performance in early and middle childhood? Trends Psychiatry Psychother. 2016;38(2):80-89. http://dx.doi.org/10.1590/2237-6089-2015-
} 0085 


\section{Introduction}

Theories have posited stress as a mechanism through which socioeconomic status (SES) and family environment exert their effects on cognition. ${ }^{1}$ However, few studies have systematically tested these determinants together. ${ }^{2,3}$ The main aim of this study was to address this gap in the literature by testing these variables in a single model that considers the direct effects of family environment on stress reactivity and on cognitive performance and investigates how stress is related to the results of cognitive assessments.

Children are exposed to vulnerabilities when their families cannot satisfactorily fulfill the basic tasks of socialization and provide them with adequate support in terms of nutrition, education and health care. ${ }^{4}$ When family dysfunction occurs at key stages of development, such as during early childhood, children are at a higher risk of delayed development. ${ }^{5,6}$ Parental care, in particular the discipline imposed by parents, verbal communication and parents' concern with the emotional needs of their children, appear to mediate (at least partially) the effects of socioeconomic status on children's emotional and cognitive development, especially at this stage of life. 4,7,8 Quality interactions between parents and children are associated with resilience in children living in stressful and impoverished environments. ${ }^{4}$ In fact, clinical programs designed to improve parenting practices in poor families at high risk of vulnerabilities improve children's behavioral, cognitive and health indicators, ${ }^{9-11}$ demonstrating that the quality of the environment in which children live is crucial to the quality of their development.

Adverse environmental conditions such as low SES can be related to higher levels of stress ${ }^{12}$ and greater irritability, depression and anxiety in the parents, which impairs interactions between parents and children. ${ }^{13-15}$ For example, maternal depression is associated with poorer cognitive performance in children, ${ }^{16-19}$ especially deficits in working memory and executive functions. ${ }^{20,21}$ Additionally, high levels of stress-related hormones have a direct effect on children's neurodevelopment. ${ }^{22}$ For example, high levels of cortisol are associated with damage in the hypothalamus and prefrontal areas ${ }^{23}$ and impaired memory and executive functioning. ${ }^{24}$ The impact of SES on working memory during childhood development seems to be mediated by stress levels. ${ }^{25-28}$

Based on empirical studies, some authors ${ }^{29,30}$ suggest multifactor models to explain the complex relationship between SES and children's cognitive development. These models include interactions between family environment and behavioral, cognitive and biological aspects of children's development. According to a model proposed by Noble et al., ${ }^{29}$ family SES has a negative relationship with stress levels. It has been observed that the lower the SES, the higher the peripheral levels of proteins related to response to stress (cortisol and catecholamine). ${ }^{31}$ In fact, interactions between parents and children and mothers' mental health can influence the physiology of children's response to stress, for example hypothalamic-pituitary-adrenal (HPA) axis activity. ${ }^{32,33}$ There is therefore evidence that these stressors affect parenting practices and the linguistic environment. In families with low SES, parents can be less consistent in their parenting practices and less involved in their children's studies and activities, which, in turn, is associated with behavioral and cognitive problems in childhood. ${ }^{34,35}$

These multifactorial models seem to offer a very good explanation for how SES and family environment affect cognitive performance, but there is little empirical data to support these theories. The objective of this study was to investigate associations between variables related to the family environment (SES, maternal mental health, and family environment) during childhood, salivary cortisol measures and performance on measures of memory and executive functioning.

\section{Method}

\section{Participants}

The sample comprised 70 children and their parents, recruited from a low-income community in a city in southern Brazil by convenience at birth and followed to school age. ${ }^{34}$ These families were assessed at two periods in the children's lives, $(A)$ early childhood (mean $[\mathrm{M}]$ age $=2.05$; standard deviation $[\mathrm{SD}]=0.05$ years) and $(B)$ school age ( $M$ age $=9.87 ;$ SD $=0.41$ years $)$. Additionally, $51.4 \%(n=36)$ of the children were girls, students in the 2 nd to 5 th grades at public schools. The families were predominantly classed as low SES. Table 1 lists descriptive data for the sample.

\section{Instruments and procedures}

All guardians signed informed consent. The study was approved by the Research Ethics Committee at the Hospital de Clínicas de Porto Alegre (protocol no. 016/2009). 


\section{Sociodemographic and clinical evaluation}

Questionnaires covering several sociodemographic variables, including family income, were administered to the parents to enable assessment of family socioeconomic status. Family environment was assessed using the Global Assessment of Relational Functioning (GARF) scale, which has been validated for the Brazilian population. ${ }^{36}$ This instrument measures the degree to which the family or the parents meet the emotional and operational needs of the family's members (5-point Likert scale).

Maternal mental health was assessed using the SelfReporting Questionnaire (SRQ-20), ${ }^{37}$ which evaluates emotional and physical symptoms associated with mental disorders. Significant psychiatric morbidity is associated with presence of eight or more of these symptoms, with sensitivity of $86.33 \%$ and specificity of $89.31 \% .{ }^{37}$ The Beck Depression Inventory (BDI) 38 was also used to evaluate depressive symptoms in mothers during their children's early childhood and the BDI for Primary Care (comprising seven items derived from the original BDI) was used when their children reached school age. ${ }^{39}$

\section{Cognitive assessments}

Cognitive instruments were administered to each school-aged child, on an individual basis, in two sessions. In the first session, the Vocabulary and Matrix Reasoning subtests of the Wechsler Abbreviated Scale of Intelligence (WASI) ${ }^{40,41}$ were administered. In the second session, the children performed cognitively challenging tasks intended to assess memory and executive functions. ${ }^{42}$ According to Dickerson \& Kemeny, ${ }^{43}$ threats to one's social esteem or social status can be stressors. The magnitude of the stress response depends on the intensity of the challenge, its context, and the presence of factors of vulnerability and protection in the individual and social environment. This framework suggests that cognitive challenge may be a particularly informative method for investigating individuals' stress responses. ${ }^{44}$

The children were also assessed with the Child Brief Neuropsychological Assessment Battery (NEUPSILININF) ${ }^{45}$ consisting of: 1 ) working memory tasks, including forward and backward digit span, pseudowords span and a visual working memory task; 2) verbal memory, including immediate recall of a word list and figures; and 3) executive function, including inhibitory control tasks such as orthographic and semantic verbal fluency and auditory go/no-go tasks. Before the assessment, the examiner established a rapport with the child (approximately five minutes) in a quiet room. The battery was structured in such a way that the tasks gradually increased in difficulty over 45 minutes.

\section{Stress evaluation}

We collected salivary cortisol at two different time points (before and after cognitive testing with the NEUPSILIN-INF - 45 minute delay). The participant placed a cotton roll under the tongue for approximately 3 minutes, until it was completely saturated with saliva. The cotton roll was then removed from the mouth by the participant, returned to the examiner and placed into a 5 $\mathrm{mL}$ syringe without the plunger. The plunger was replaced in the syringe, and the saliva sample was collected into a labeled plastic tube. The minimum volume of saliva collected for each session was $0.5 \mathrm{~mL}$.

After the collection protocol, all samples were centrifuged and stored at $-80^{\circ} \mathrm{C}$ until analysis. Samples were analyzed in duplicate by radioimmunoassay (CoatA-Count ${ }^{\circledR}$ Cortisol Kit, Siemens Medical Solutions Diagnostics, Los Angeles, CA, USA). The sensitivity of this assay was estimated at $0.1 \mathrm{nM}$. The coefficients of intra and inter-assay variation were less than $10 \%$. The results of each sample collection time were expressed in $\mathrm{nmol} / \mathrm{L}$. It is known that cortisol levels increase in the morning and decrease during the day, ${ }^{46}$ so we decided to conduct the tests between 10:00 a.m. and 03:00 p.m. to minimize the effect of circadian phases.

\section{Results}

The characteristics of the sample are listed in Table 1. Most families were from low SES backgrounds (91.2\%), with SES characterized by family income. It was found that $19 \%$ of the mothers had symptoms of mental illness (SRQ-20) during their children's early childhood, rising to $32 \%$ when their children were school age. Additionally, $26 \%$ of mothers reported depressive symptoms at both stages of the study.

\section{Family environment vs. cognitive perfor- mance}

Exploratory analyses were performed to test for correlations between measurements of family environment (family income, SRQ-20, BDI and GARF) assessed in early childhood and at school age, cortisol levels before and after cognitive testing and the children's performance in memory and executive function tasks at school age, using IQ as a control variable. This analysis showed that maternal psychopathology scores during the early years and school age of children were negatively 
Table 1 - Characteristics of the sample of children $(n=70)$. Age in years, years' schooling, IQ performance (WASI), cortisol levels (before and after cognitive testing), family income, maternal mental health (SRQ-20, BDI and BDI-PC), family environment (GARF) at early childhood and when child was school age and results of cognitive tasks.

\begin{tabular}{|c|c|c|c|c|}
\hline & Min & Max & Mean & SD \\
\hline \multicolumn{5}{|l|}{ Child variables } \\
\hline Early childhood (age in years) & 2 & 2.1 & 2.05 & 0.05 \\
\hline School age (in years) & 9 & 10 & 9.87 & 0.41 \\
\hline Educational level (years of education) & 2 & 5 & 3.56 & 0.65 \\
\hline IQ (WASI - percentile) & 59 & 107 & 79.54 & 11.52 \\
\hline Cortisol level before cognitive testing ( $\mathrm{nmol} / \mathrm{L}$ ) & 1.30 & 18.35 & 4.34 & 0.19 \\
\hline Cortisol level after cognitive testing (nmol/L) & 3.48 & 65.20 & 17.73 & 13.90 \\
\hline \multicolumn{5}{|l|}{ Family variables (early childhood) } \\
\hline Family income (minimum wages) & 0.80 & 8.05 & 3.77 & 1.67 \\
\hline Maternal psychopathology (SRQ-20) & 0 & 16 & 4.67 & 3.54 \\
\hline Maternal depression (BDI) & 0 & 34 & 8.41 & 8.26 \\
\hline Family environment (GARF) & 15 & 90 & 69.12 & 16.35 \\
\hline \multicolumn{5}{|l|}{ Family variables (when child school age) } \\
\hline Family income (minimum wages) & 0.21 & 6.45 & 2.68 & 1.56 \\
\hline Maternal psychopathology (SRQ-20) & 0 & 15 & 6.35 & 4.75 \\
\hline Maternal depression (BDI-PC) & 0 & 17 & 4.21 & 4.86 \\
\hline Family environment (GARF) & 20 & 90 & 66.19 & 18.73 \\
\hline \multicolumn{5}{|l|}{ Cognitive tasks (when child school age) } \\
\hline \multicolumn{5}{|l|}{ Memory } \\
\hline Immediate recall & 1 & 8 & 4.89 & 1.45 \\
\hline Delayed recall & 0 & 7 & 3.62 & 1.41 \\
\hline Forward digit span & 7 & 24 & 17.86 & 3.54 \\
\hline Backward digit span & 0 & 25 & 15.26 & 5.67 \\
\hline Pseudoword span & 3 & 19 & 10.92 & 3.02 \\
\hline Visuospatial WM & 4 & 28 & 17.62 & 7.37 \\
\hline Visuoverbal WM & 3 & 9 & 5.85 & 1.36 \\
\hline \multicolumn{5}{|l|}{ Executive functions } \\
\hline Orthographic verbal fluency & 1 & 15 & 7.02 & 2.84 \\
\hline Semantic verbal fluency & 4 & 23 & 12.95 & 3,73 \\
\hline Go/no-go task & 34 & 60 & 54.27 & 4.49 \\
\hline
\end{tabular}

BDI = Beck Depression Inventory; BDI-PC = Beck Depression Inventory for Primary Care; GARF = Global Assessment of Relational Functioning; IQ = intelligence quotient; Max = maximum; Min = minimum; SD = standard deviation; SRQ-20 = Self Reporting Questionnaire; WASI = Wechsler Abbreviated Scale of Intelligence; $\mathrm{WM}=$ working memory.

correlated with performance in a working memory task - forward digit span (SRQ-20 in early childhood: $r=-0.41 ; p=0.022)$ - and executive functions - go/ no-go task (BDI at school age: $r=-0.41 ; p=0.024$ ). Family functioning (GARF) at school age was positively correlated with performance in the go/no-go task ( $r$ $=0.39 ; \mathrm{p}=0.03$ ) and income in early childhood was positively correlated with performance in executive functions - semantic verbal fluency $(r=0.32 ; p=0.03)$ and go/no-go task $(r=0.32 ; p=0.034)$.

\section{Family environment vs. stress}

There was no significant difference between cortisol measures in the morning and the afternoon (cortisol pretest: $\mathrm{t}_{68}=0.53, \mathrm{p}=0.59$; cortisol posttest: $\mathrm{t}_{68}=0.69$, $p=0.49$ ). Additionally, family environment variables correlated with final and initial cortisol measurements. Symptoms of maternal psychopathology in early childhood were positively correlated with cortisol levels before testing - SRQ-20 ( $r=0.37 ; \mathrm{p}=0.005)$ and BDI $(r=0.28 ; p=0.033)$. Results for the family functioning scale (GARF) assessed in early childhood correlated with cortisol measurement after cognitive testing ( $r=$ $-0.44 ; p=0.015$ ) and the greater the degree of family dysfunction, the higher the level of stress after cognitive testing. Depressed mothers' children had less cortisol variation $\left(\mathrm{t}_{54}=-1.33, \mathrm{p}=0.015\right)$ and higher cortisol levels prior to neuropsychological testing ( $M=5.48, S D$ $=4.64$ vs. $\mathrm{M}=3.85, \mathrm{SD}=2.57, \mathrm{t}_{54}=1.65, \mathrm{p}=0.025$ ) than children with non-depressive mothers (as assessed by the BDI). The same was observed in relation to family 
functioning. Children from families with a greater degree of dysfunction ( $n=12$ ) had a higher initial cortisol level in relation to families with median $(n=36)$ and low ( $n$ $=21)$ dysfunction $\left(F_{2,63}=12.10 ; p=0.001 ; \eta^{2}=0.76\right)$ in early childhood and at school-age $\left(F_{2,53}=3.68, p=\right.$ $0.004 ; \eta^{2}=0.12$ ).

\section{Stress vs. cognitive performance}

We conducted an analysis of repeated measures to investigate the differences between cortisol levels measured before and after cognitive testing. Intrasubject $\left(F_{1,66}=117.78 ; \mathrm{p}<0.001 ; \eta^{2}=0.64\right)$ and inter-subject $\left(F_{1,66}=1140.2 ; p<0.001 ; \eta^{2}=0.94\right)$ differences were detected. The post-neuropsychological testing cortisol level was more than twice the pre-test cortisol level $(M=0.55, S D=0.27$ vs. $M=1.13, S D$ $=0.33$ ). This finding is to be expected in this situation because neuropsychological assessment can be seen as a cognitive challenge inducing a stress response. In the correlation analyses, post-test cortisol (but not pre-test cortisol) was negatively associated with performance in the tasks testing visuoverbal memory $(r=-0.32 ; p=$ $0.012)$, visuospatial working memory $(r=-0.30 ; p=$ $0.019)$, forward digit span $(r=-0.29 ; p=0.023)$ and delayed episodic memory $(r=-0.35 ; p=0.006)$.

\section{Family environment, stress and cognitive performance models}

Finally, a hierarchical multiple regression was performed, including environment variables assessed in early childhood (step 1) and at school age (step 2), change in child's cortisol levels (step 3) and IQ (step 4) as independent variables and treating performance in cognitive tasks as dependent variables. Table 2 only lists results that were statistically significant. As can be observed from this table, family income during early childhood contributed to performance in pseudoword span, in immediate episodic memory and in the go/ no-go task. Mother's depression and mental health during early childhood were predictors of go/no-go task performance. Family income in early childhood and at school age contributed to forward digit span and visuoverbal memory performance. Cortisol level after cognitive testing was a predictor of visuospatial working memory, delayed episodic memory, visuoverbal memory and forward digit span performance. Performance in the other cognitive tasks was only explained by IQ.

\section{Discussion}

This study related aspects of the family environment to a stress response mechanism in children. Cortisol levels were expected to increase in response to the stress caused by cognitive tasks (due to the progressive cognitive challenge). ${ }^{43}$ We found that the higher the mother's psychopathology assessment score as tested during her child's early childhood, the higher the child's cortisol levels at school age before the cognitive challenge. Regarding the family environment, the higher the degree of family dysfunction, the higher the child's cortisol levels after cognitive testing, which suggest that children from maladaptive environments have differences in reactivity to stress. Cortisol levels are related to aspects of family environment, ${ }^{47,48}$ since interactions between parents and children and mothers' mental health can influence the physiology of their children's response to stress ${ }^{28}$ and, consequently, their health. ${ }^{15,49,50}$ Some studies have associated parental support and maternal psychopathology in the child's first year of life - when the HPA axis is very labile - with prolonged activations of the HPA axis to respond to daily stressful events. ${ }^{32,51}$ Although response to stress is considered an adaptive function, ${ }^{52}$ chronic exposure to high concentrations of glucocorticoids contributes to development of physical diseases ${ }^{15,50,53,54}$ and psychological and cognitive dysfunctions ${ }^{55}$ that may persist into adulthood. ${ }^{26,56,57}$

Early exposure to maternal depressive symptoms also negatively affects children's development of executive functions and working memory. ${ }^{20,21,58}$ A study by Hughes et al., ${ }^{20}$ for example, showed that maternal depression in the mothers of two-year old children was a predictor of performance in executive function tasks (inhibitory control) and working memory four years later, which is similar to the findings observed in the present study. Depressed mothers are less likely to respond to their children's stimuli (both by actions and vocalizations) or to get involved in interactive activities, which may impact their verbal skills. ${ }^{59}$ Furthermore, early chronic stress and family dysfunction affect the child's development process, producing a cascading effect, in which child maladaptation to the hostile environment also contributes to family dysfunction and parents' psychopathology, ${ }^{60}$ creating a cycle of maladaptation that is maintained (or gets worse) over time. ${ }^{61}$

The data from this study corroborate evidence from previous studies on the existence of a relationship between memory deficit and increased stress in children. ${ }^{62-65}$ Stress affects skills that require a conscious effort in information processing, reducing cognitive efficiency. ${ }^{65}$ With regard to acute stress, the reduced cognitive efficiency could be considered an adaptive 
Stress, SES and children's cognitive performance - Piccolo et al.

Table 2 - Hierarchical linear regression model for cognitive performance

\begin{tabular}{|c|c|c|c|c|c|c|}
\hline & $\mathbf{R}^{2}$ & $\mathbf{R}_{\text {adi }}^{2}$ & $\mathbf{F}$ & df & B & p-value \\
\hline \multicolumn{7}{|l|}{ Verbal - immediate recall } \\
\hline Step 1 & 0.08 & 0.02 & 1.34 & 4 & & \\
\hline Income* & & & & & 0.22 & 0.07 \\
\hline SRQ-20* & & & & & -0.03 & 0.87 \\
\hline BDI* & & & & & 0.23 & 0.14 \\
\hline GARF* & & & & & 0.04 & 0.78 \\
\hline Step 2 & 0.17 & 0.06 & 1.75 & 4 & & \\
\hline Incomet & & & & & $-0.28 \neq$ & 0.04 \\
\hline SRQ-20† & & & & & 0.11 & 0.50 \\
\hline $\mathrm{BDI}+$ & & & & & -0.02 & 0.92 \\
\hline GARF' & & & & & 0.26 & 0.11 \\
\hline Step 3 & 0.20 & 0.07 & 1.24 & 2 & & \\
\hline Pre-test cortisol & & & & & -0.13 & 0.28 \\
\hline Post-test cortisol & & & & & -0.06 & 0.61 \\
\hline Step 4 & 0.33 & 0.20 & 10.90 & 1 & & \\
\hline IQ & & & & & $0.38 \neq$ & 0.02 \\
\hline \multicolumn{7}{|c|}{ Verbal memory - delayed recall } \\
\hline Step 1 & 0.06 & 0.01 & 1.10 & 4 & & \\
\hline Income* & & & & & 0.13 & 0.29 \\
\hline SRQ-20* & & & & & 0.17 & 0.33 \\
\hline BDI* & & & & & 0.03 & 0.85 \\
\hline GARF* & & & & & -0.01 & 0.95 \\
\hline Step 2 & 0.07 & -0.05 & 0.16 & 4 & & \\
\hline Incomet & & & & & $-0,03$ & 0.85 \\
\hline SRQ-20† & & & & & -0.10 & 0.57 \\
\hline $\mathrm{BDI}+$ & & & & & 0.07 & 0.68 \\
\hline GARF† & & & & & -0.01 & 0.94 \\
\hline Step 3 & 0.18 & 0.04 & 3.98 & 2 & & \\
\hline Pre-test cortisol & & & & & -0.08 & 0.51 \\
\hline Post-test cortisol & & & & & $-0.33 \neq$ & 0.02 \\
\hline Step 4 & 0.22 & 0.07 & 2.94 & 1 & & \\
\hline IQ & & & & & $0.22 \neq$ & 0.09 \\
\hline \multicolumn{7}{|l|}{ Visuoverbal memory } \\
\hline Step 1 & 0.07 & 0.01 & 1.19 & 4 & & \\
\hline Income* & & & & & 0.15 & 0.21 \\
\hline SRQ-20* & & & & & -0.34 & 0.84 \\
\hline BDI* & & & & & 0.05 & 0.74 \\
\hline GARF* & & & & & $0.42 \neq$ & 0.003 \\
\hline Step 2 & 0.09 & -0.03 & 0.38 & 4 & & \\
\hline Incomet & & & & & 0.02 & 0.91 \\
\hline SRQ-20† & & & & & 0.07 & 0.67 \\
\hline $\mathrm{BDI}+$ & & & & & 0.05 & 0.78 \\
\hline GARF† & & & & & -0.04 & 0.81 \\
\hline Step 3 & 0.28 & 0.16 & 7.69 & 2 & & \\
\hline Pre-test cortisol & & & & & -0.03 & 0.80 \\
\hline Post-test cortisol & & & & & $-0.47 \neq$ & 0.001 \\
\hline Step 4 & 0.29 & 0.16 & 1.26 & 1 & & \\
\hline IQ & & & & & 0.13 & 0.27 \\
\hline \multicolumn{7}{|l|}{ Forward digit span } \\
\hline Step 1 & 0.01 & -0.05 & 0.23 & 4 & & \\
\hline Income* & & & & & 0.15 & 0.20 \\
\hline SRQ-20* & & & & & 0.02 & 0.90 \\
\hline BDI* & & & & & 0.05 & 0.75 \\
\hline GARF* & & & & & $0.35 \neq$ & 0.01 \\
\hline Step 2 & 0.18 & 0.07 & 2.97 & 4 & & \\
\hline Incomet & & & & & 0.18 & 0.19 \\
\hline
\end{tabular}







process to compensate for the increased automatic processing effectiveness when potentially negative and threatening events occur. ${ }^{66}$ However, prolonged stress may cause overactivation of this mechanism, resulting in impairment of cognitive functioning.

Evidence from studies on explicit memory suggest that information retrieval processes are particularly susceptible to the adverse effects of stress and increased cortisol levels, while consolidation processes can be impaired by stress. ${ }^{67-69}$ There is also evidence that stress has a direct effect on development of children's brains, ${ }^{52}$ affecting their operation ${ }^{70}$ and reaching prefrontal regions that are related to self-regulation and attention. ${ }^{71}$ Inhibitory control, which concerns ability to inhibit competitive responses, is related to self-control (self-regulation) and is susceptible to environmental influences. ${ }^{20}$ Low SES during childhood is linked with family dysfunction and, consequently, to poor self-control in adulthood, and is also associated with perceived stress. ${ }^{49}$

Another aspect that relates both to maternal mental health and to family environment is family income, ${ }^{34}$ which was also a predictor of memory and executive function performance in this study. This indicator has been particularly associated with children's development of language and vocabulary ${ }^{72}$ - which are essential for development of other cognitive functions ${ }^{73,74}$ - for example, via the availability of books and other literature resources, computers and parental communication. ${ }^{14}$ Furthermore, children living in deprived neighborhoods are more likely to have poor nutrition and are more prone to health problems, in addition to being exposed to pollutants and violence, ${ }^{15}$ which have a direct impact on their cognitive development and general health.

Limitations of the study include the relatively small size of the sample and the particular characteristics of the participants. There is a degree of homogeneity to the sample in terms of SES (predominantly low SES) and the children assessed study at schools on the outskirts of city where there is a high incidence of psychopathologies among parents and children and this may have affected the results, since we do not have children from high SES families for comparison. Additionally, although widely used, cortisol levels measured in saliva, blood or urine can be highly variable because they are likely to be affected by several factors that may occur shortly before sampling. ${ }^{75}$

\section{Conclusion}

As we report in this study, different factors of the family environment affect performance in certain neuropsychological systems differently. We know that memory (episodic, working and semantic) and executive functions $s^{3,34,76}$ are more susceptible to influence from the environment and stress due to their complexity and prolonged development. ${ }^{26,77}$ We can assume that income is important because it limits the conditions for stimulation, nutrition and housing and access to better schools and to materials and activities that favor cognitive development. ${ }^{78}$ Family functioning is relevant since it affects parenting style and how families deal with stressful situations. ${ }^{79}$ Maternal mental health influences the way that mothers take care of their children and the extent to which they are able to get involved in their activities. All of these factors interact dynamically and it is not any one of them in isolation that can explain the effects on children's development, rather the sum of all of them produces a unique contribution in each case. ${ }^{61}$

The results of this study provide evidence for theorists who wish to attempt to explain the association between environment and performance in cognitive tasks, through mediation by family and stress factors. ${ }^{29,80}$ This is a pioneering study in Brazil that has related early childhood factors with the results of memory and executive function assessments in school-age children. Knowledge in this field may support interventions in the public health system designed both to improve the quality of life of the population and to prevent cognitive deficits, through providing assistance to poor families, for example. Interventional studies have shown that improvement in the quality of family environment has a positive impact on people's health status, reducing inflammatory processes for example, ${ }^{49}$ and improves their emotional and cognitive development. ${ }^{9-11}$ Therefore, the present study provides information on the living conditions of a population that should benefit from improvements in the healthcare system of the community represented by this sample, based on the needs indicated by studying that sample.

\section{Acknowledgments}

The authors thank Dr. Natalie H. Brito, postdoctoral research fellow at Columbia University Medical Center, NY, USA, for her editorial support during the preparation of this manuscript and for her insightful suggestions to improve the quality this article.

\section{References}

1. McEwen BS, Stellar E. Stress and the individual. Mechanisms leading to disease. Arch Intern Med. 1993;153:2093-101.

2. Blair C, Granger DA, Willoughby M, Mills-Koonce R, Cox M, Greenberg MT, et al. Salivary cortisol mediates effects of poverty and parenting on executive functions in early childhood. Child 
Dev. 2011;82:1970-84.

3. Piccolo LR, Sbicigo JB, Grassi-Oliveira R, Salles JF. Do socioeconomic status and stress reactivity really impact neurocognitive performance? Psychol Neurosci. 2014;7:567-75.

4. Gunnar MR, Fisher PA; Early Experience, Stress, and Prevention Network. Bringing basic research on early experience and stress neurobiology to bear on preventive interventions for neglected and maltreated children. Dev Psychopathol. 2006;18:651-77.

5. Brooks-Gunn J, Duncan GJ. The effects of poverty on children. Future Child. 1997; 7:55-71

6. Feldman R, Eidelman AI. Biological and environmental initial conditions shape the trajectories of cognitive and social-emotional development across the first years of life. Dev Sci. 2009;12:194200.

7. Linver MR, Brooks-Gunn J, Kohen DE. Family processes as pathways from income to young children's development. Dev Psychol. 2002;38:719-34

8. McLoyd VC. Socioeconomic disadvantage and child development. Am Psychol. 1998;53:185-204.

9. Fisher PA, Gunnar MR, Chamberlain P, Reid JB. Preventive intervention for maltreated preschool children: impact on children's behavior, neuroendocrine activity, and foster parent functioning. J Am Acad Child Adolesc Psychiatry. 2000;39:135664.

10. Olds $D$, Henderson $C R$ Jr, Cole R, Eckenrode J, Kitzman $H$, Luckey $D$, et al. Long-term effects of nurse home visitation on children's criminal and antisocial behavior: 15-year follow-up of a randomized controlled trial. JAMA. 1998;280:1238-44.

11. van den Boom DC. The influence of temperament and mothering on attachment and exploration: an experimental manipulation of sensitive responsiveness among lower-class mothers with irritable infants. Child Dev. 1994;65:1457-77.

12. Conger RD, Donnellan MB. An interactionist perspective on the socioeconomic context of human development. Annu Rev Psychol. 2007;58:175-99.

13. Grolnick WS, Gurland ST, DeCourcey W, Jacob K. Antecedents and consequences of mothers' autonomy support: an experimental investigation. Dev Psychol. 2002;38:143-55.

14. Hackman DA, Farah MJ, Meaney MJ. Socioeconomic status and the brain: mechanistic insights from human and animal research. Nat Rev Neurosci. 2010;11:651-9.

15. Chen E, Miller GE. Socioeconomic status and health: mediating and moderating factors. Annu Rev Clin Psychol. 2013;9:723-49.

16. Cogill SR, Caplan HL, Alexandra H, Robson KM, Kumar R. Impact of maternal postnatal depression on cognitive development of young children. Br Med J (Clin Res Ed). 1986;292:1165-7.

17. Hay DF, Pawlby $S$, Sharp $D$, Asten $P$, Mills $A$, Kumar R. Intellectual problems shown by 11-year-old children whose mothers had postnatal depression. J Child Psychol Psychiatry. 2001;42:87189.

18. Kurstjens S, Wolke D. Effects of maternal depression on cognitive development of children over the first 7 years of life. J Child Psychol Psychiatry. 2001;42:623-36.

19. Murray L, Arteche A, Fearon P, Halligan S, Croudace T, Cooper P. The effects of maternal postnatal depression and child sex on academic performance at age 16 years: a developmental approach. J Child Psychol Psychiatry. 2010;51:1150-9.

20. Hughes C, Roman G, Hart MJ, Ensor R. Does maternal depression predict young children's executive function? - a 4-year longitudinal study. J Child Psychol Psychiatry. 2013;54:169-77.

21. Klimes-Dougan $B$, Ronsaville $D$, Wiggs EA Martinez PE. Neuropsychological functioning in adolescent children of mothers with a history of bipolar or major depressive disorders. Biol Psychiatry. 2006;60:957-65.

22. McEwen BS. Protection and damage from acute and chronic stress: allostasis and allostatic overload and relevance to the pathophysiology of psychiatric disorders. Ann N Y Acad Sci. 2004;1032:1-7.

23. Chan M, Chen E, Hibbert AS, Wong JH, Miller GE. Implicit measures of early-life family conditions: relationships to psychosocial characteristics and cardiovascular disease risk in adulthood. Health Psychol. 2011;30:570-8.

24. Liston C, McEwen BS, Casey BJ. Psychosocial stress reversibly disrupts prefrontal processing and attentional control. Proc Natl Acad Sci U S A. 2009;106:912-7.

25. Lupien SJ, King S, Meaney MJ, McEwen BS. Can poverty get under your skin? basal cortisol levels and cognitive function in children from low and high socioeconomic status. Dev Psychopathol. 2001;13:653-76.

26. Evans GW, Schamberg MA. Childhood poverty, chronic stress, and adult working memory. Proc Natl Acad Sci U S A. 2009;106:65459.

27. Lupien SJ, McEwen BS, Gunnar MR, Heim C. Effects of stress throughout the lifespan on the brain, behaviour and cognition. Nat Rev Neurosci. 2009;10:434-45.

28. McEwen BS, Gianaros PJ. Central role of the brain in stress and adaptation: links to socioeconomic status, health, and disease. Ann N Y Acad Sci. 2010;1186:190-22.

29. Noble KG, Houston SM, Kan E, Sowell ER. Neural correlates of socioeconomic status in the developing human brain. Dev Sci. 2012;15:516-27.

30. Willingham DT. Why does family wealth affect learning? Am Educ. 2012;36:33-9.

31. Lupien SJ, Parent S, Evans AC, Tremblay RE, Zelazo PD, Corbo V, et al. Larger amygdala but no change in hippocampal volume in 10-year-old children exposed to maternal depressive symptomatology since birth. Proc Natl Acad Sci U S A. 2011;108:14324-9.

32. Albers EM, Riksen-Walraven JM, Sweep FC, de Weerth C. Maternal behavior predicts infant cortisol recovery from a mild everyday stressor. J Child Psychol Psychiatry. 2008;49:97-103.

33. Lupien SJ, King S, Meaney MJ, McEwen BS. Child's stress hormone levels correlate with mother's socioeconomic status and depressive state. Biol Psychiatry. 2000;48:976-80.

34. Piccolo LR, Falceto OG, Fernandes CL, Levandowski DC, GrassiOliveira R, Salles JF. Variáveis psicossociais e desempenho em leitura de crianças de baixo nível socioeconômico. Psic Teor e Pesq. 2012;28:389-98.

35. Chazan-Cohen R, Raikes H, Brooks-Gunn J, Ayoub C, Pan BA, Kisker $\mathrm{EE}$, et al. Low-income children's school readiness: parent contributions over the first five years. Early Educ Dev. 2009;20:958-77.

36. Falceto OG, Busnello ED, Bozzetti MC. [Validation of diagnostic scales of family functioning for use in primary health care services]. Rev Panam Salud Publica. 2000; 7:255-63.

37. Beusenberg M, Orley JH, Health WHOD of M. A User's guide to the self reporting questionnaire (SRQ/compiled by M. Beusenberg and J. Orley. Geneva: World Health Organization (WHO); 1994.

38. Beck AT, Steer RA, Brown G. Manual for the Beck Depression Inventory-II. San Antonio: Psychological Corporation; 1996

39. Steer RA, Cavalieri TA, Leonard DM, Beck AT. Use of the Beck Depression Inventory for Primary Care to screen for major depression disorders. Gen Hosp Psychiatry. 1999;21:106-11.

40. Heck VS, Yates DB, Poggere LC, Tosi SP, Bandeira DR, Trentini CM. Validação dos subtestes verbais da versão de adaptação da WASI. Aval Psicol. 2009;8:33-42

41. The Psychological Corporation. Wechsler abbreviated scale of intelligence manual. San Antonio: Psychological Corporation; 1999.

42. Gotlib IH, LeMoult J, Colich NL, Foland-Ross LC, Hallmayer J, Joorman J, et al. Telomere length and cortisol reactivity in children of depressed mothers. Mol Psychiatry. 2015;20:615-20.

43. Dickerson SS, Kemeny ME. Acute stressors and cortisol responses: a theoretical integration and synthesis of laboratory research. Psychol Bull. 2004;130:355-91.

44. Neupert SD, Miller LM, Lachman ME. Physiological reactivity to cognitive stressors: variations by age and socioeconomic status. Int J Aging Hum Dev. 2006;62:221-35.

45. Salles JF de, Fonseca RP, Cruz-Rodrigues C, Mello CB, Barbosa T, Miranda MC. Desenvolvimento do Instrumento de Avaliação Neuropsicológica Breve Infantil NEUPSILIN-INF. Psico-USF. 2011;16:297-305.

46. Hucklebridge $F$, Hussain $T$, Evans $P$, Clow $A$. The diurnal patterns of the adrenal steroids cortisol and dehydroepiandrosterone (DHEA) in relation to awakening. Psychoneuroendocrinology. 2005;30:51-7.

47. Chen E, Cohen S, Miller GE. How low socioeconomic status affects 2-year hormonal trajectories in children. Psychol Sci. 2010;21:31-7.

48. Dowd JB, Simanek AM, Aiello AE. Socio-economic status, cortisol and allostatic load: a review of the literature. Int J Epidemiol. 2009;38:1297-309.

49. Hostinar CE, Ross KM, Chen E, Miller GE. Modeling the association between lifecourse socioeconomic disadvantage and systemic inflammation in healthy adults: the role of self-control. Health Psychol. 2015;34:580-90.

50. Best JR, Miller PH, Jones LL. Executive functions after age 5: changes and correlates. Dev Rev. 2009;29:180-200.

51. Halligan SL, Herbert J, Goodyer I, Murray L. Disturbances in morning cortisol secretion in association with maternal postnatal 
depression predict subsequent depressive symptomatology in adolescents. Biol Psychiatry. 2007;62:40-6.

52. McEwen BS, Seeman T. Protective and damaging effects of mediators of stress. Elaborating and testing the concepts of allostasis and allostatic load. Ann N Y Acad Sci. 1999;896:30-47.

53. Chen E, Hanson MD, Paterson LQ, Griffin MJ, Walker HA, Miller GE. Socioeconomic status and inflammatory processes in childhood asthma: the role of psychological stress. J Allergy Clin Immunol. 2006;117:1014-20.

54. Chen E, Miller GE, Kobor MS, Cole SW. Maternal warmth buffers the effects of low early-life socioeconomic status on pro-inflammatory signaling in adulthood. Mol Psychiatry. 2011;16:729-37.

55. Lupien S, McEwen B. The acute effects of corticosteroids on cognition: integration of animal and human model studies. Brain Res Brain Res Rev. 1997;24:1-27.

56. Evans GW, Fuller-Rowell TE. Childhood poverty, chronic stress, and young adult working memory: the protective role of selfregulatory capacity. Dev Sci. 2013;16:688-96.

57. Miller GE, Lachman ME, Chen E, Gruenewald TL, Karlamangla AS, Seeman TE. Pathways to resilience: maternal nurturance as a buffer against the effects of childhood poverty on metabolic syndrome at midlife. Psychol Sci. 2011;22:1591-9.

58. Micco JA, Henin A, Biederman J, Rosenbaum JF, Petty $C$, Rindlaub $\mathrm{LA}$, et al. Executive functioning in offspring at risk for depression and anxiety. Depress Anxiety. 2009;26:780-90.

59. Field T, Pickens J, Prodromidis M, Malphurs J, Fox N, Bendell D, et al. Targeting adolescent mothers with depressive symptoms for early intervention. Adolescence. 2000;35:381-414.

60. Obradovic J, Burt KB, Masten AS. Testing a dual cascade model linking competence and symptoms over 20 years from childhood to adulthood. J Clin Child Adolesc Psychol. 2010;39:90-102.

61. Enlow MB, Blood E, Egeland B. Sociodemographic risk, developmental competence, and PTSD symptoms in young children exposed to interpersonal trauma in early life. J Trauma Stress. 2013;26:686-94.

62. Lupien SJ, Gillin CJ, Hauger RL. Working memory is more sensitive than declarative memory to the acute effects of corticosteroids: a dose-response study in humans. Behav Neurosci. 1999;113:42030.

63. Oei NY, Everaerd WT, Elzinga BM, van Well $S$, Bermond $B$. Psychosocial stress impairs working memory at high loads: an association with cortisol levels and memory retrieval. Stress. 2006; 9:133-41.

64. Schoofs D, Preuss D, Wolf OT. Psychosocial stress induces working memory impairments in an n-back paradigm. Psychoneuroendocrinology. 2008;33:643-53.

65. Schwabe L, Böhringer A, Wolf OT. Stress disrupts contextdependent memory. Learn Mem. 2009;16:110-3.

66. de Kloet ER, Oitzl MS, Joëls M. Stress and cognition: are corticosteroids good or bad guys? Trends Neurosci. 1999;22:4226.
67. Het S, Ramlow G, Wolf OT. A meta-analytic review of the effects of acute cortisol administration on human memory. Psychoneuroendocrinology. 2005;30:771-84.

68. Lupien SJ, Schramek TE. The differential effects of stress on memory consolidation and retrieval: a potential involvement of reconsolidation? Theoretical comment on Beckner et al. (2006). Behav Neurosci. 2006;120:735-8.

69. Beckner VE, Tucker DM, Delville Y, Mohr DC. Stress facilitates consolidation of verbal memory for a film but does not affect retrieval. Behav Neurosci. 2006;120:518-27.

70. Noble KG, Korgaonkar MS, Grieve SM, Brickman AM. Higher education is an age-independent predictor of white matter integrity and cognitive control in late adolescence. Dev Sci. 2013;16:653-64.

71. Lawson GM, Duda JT, Avants BB, Wu J, Farah MJ. Associations between children's socioeconomic status and prefrontal cortical thickness. Dev Sci. 2013;16:641-52.

72. Piccolo $L$ da $R$, Salles JF. Vocabulário e memória de trabalho predizem desempenho em leitura de crianças. Psicol Teor Prat. 2013;15:180-91.

73. Peeters M, Verhoeven L, de Moor J, van Balkom H, van Leeuwe J. Home literacy predictors of early reading development in children with cerebral palsy. Res Dev Disabil. 2009;30:445-61.

74. Kim Y-S. The relationship between home literacy practices and developmental trajectories of emergent literacy and conventional literacy skills for Korean children. Read Writ. 2007;22:57-84.

75. Stalder T, Kirschbaum C. Analysis of cortisol in hair--state of the art and future directions. Brain Behav Immun. 2012;26:1019-29.

76. Hackman DA, Farah MJ. Socioeconomic status and the developing brain. Trends Cogn Sci. 2009;13:65-73.

77. Noble KG, Houston SM, Brito NH, Bartsch H, Kan E, Kuperman $\mathrm{JM}$, et al. Family income, parental education and brain structure in children and adolescents. Nat Neurosci. 2015;18:773-8.

78. Forns J, Julvez J, García-Esteban R, Guxens M, Ferrer M, Grellier ' J, et al. Maternal intelligence-mental health and child neuropsychological development at age 14 months. Gac Sanit. 2012;26:397-404

79. Power TG. Stress and coping in childhood: the parents' role. Parent Sci Pract. 2004;4:271-317.

80. McEwen BS. Protective and damaging effects of stress mediators. N Engl J Med. 1998;338:171-9.

\section{Correspondence:}

Luciane da Rosa Piccolo

Universidade Federal do Rio Grande do Sul (UFRGS)

Rua Ramiro Barcelos, 2600

90035-003 - Porto Alegre, RS - Brazil

Tel. : + 55 (51) 8445.1815

E-mail: lucianepiccolo@gmail.com 